\title{
Humanin and age-related diseases: a new link?
}

\author{
Zhenwei Gong ${ }^{1,2}$, Emir Tas ${ }^{2}$ and Radhika Muzumdar ${ }^{1,2,3 *}$ \\ 1 Department of Pediatrics, University of Pittsburgh School of Medicine, Pittsburgh, PA, USA \\ ${ }^{2}$ Department of Pediatrics, Division of Pediatric Endocrinology, Children's Hospital of Pittsburgh of UPMC, Pittsburgh, PA, USA \\ ${ }^{3}$ Department of Cell Biology, University of Pittsburgh School of Medicine, Pittsburgh, PA, USA
}

\section{Edited by:}

Irene Netchine, Université Pierre et Marie Curie, France

Reviewed by:

Lars Sävendahl, Karolinska University Hospital, Sweden

Alan David Rogol, University of

Virginia, USA

*Correspondence:

Radhika Muzumdar, Department of Pediatrics, Children's Hospital of Pittsburgh of UPMC, University of

Pittsburgh School of Medicine, One Children's Hospital Drive, 4401 Penn

Avenue, Pittsburgh, PA 15224, USA e-mail: radhika.muzumdar@chp.edu
Humanin (HN) is 24-amino acid mitochondria-associated peptide. Since its initial discovery over a decade ago, a role for $\mathrm{HN}$ has been reported in many biological processes such as apoptosis, cell survival, substrate metabolism, inflammatory response, and response to stressors such as oxidative stress, ischemia, and starvation. $\mathrm{HN}$ and its potent analogs have been shown to have beneficial effects in many age-related diseases including Alzheimer's disease, stroke, diabetes, myocardial ischemia and reperfusion, atherosclerosis, amyotrophic lateral sclerosis, and certain types of cancer both in vitro and in vivo. More recently, an association between HN levels, growth hormone/insulin-like growth factor-1 (GH/IGF axis), and life span was demonstrated using various mouse models with mutations in the $\mathrm{GH} / \mathrm{IGF}$ axis. The goal of this review is to summarize the current understanding of the role of $\mathrm{HN}$ in aging and age-related diseases.

Keywords: humanin, aging, age-related disease

\section{INTRODUCTION}

Humanin (HN) is a novel, 24-amino acid polypeptide with proven effects on cell survival, metabolism, response to stressors, and inflammation in vivo and in vitro. It was discovered in 2001, using a modified "death-trap" screening, in the unaffected occipital brain of a patient with sporadic Alzheimer's disease (AD) (1). Since then, it has been identified in a wide range of tissues including testes, colon, hypothalamus, heart, liver, skeletal muscle, kidney, and vascular wall (2-6). Levels of $\mathrm{HN}$ are measurable in plasma, cerebrospinal fluid (CSF), and seminal fluid indicating that it is a secreted protein (4, 7-9), though it is still unclear which tissue(s) contributes to the circulating $\mathrm{HN}$ pool.

Humanin is believed to be encoded from a small open reading frame (ORF) in the mitochondrial (mt) DNA within the $16 \mathrm{~S}$ ribosomal RNA coding region. However, there are mitochondrial pseudogenes within the nuclear DNA sequences with great resemblance to HN-encoding small ORF (10). The site of translation of $\mathrm{HN}$ has not been fully identified yet and the length of HN molecule would differ based on the site of translation. Because of the differences in translational machinery between the mitochondria and the cytosol, it will be a 21 amino acid peptide if translation occurs in mitochondria, while cytoplasmic translation will yield a 24-amino acid long polypeptide. Both 21 and 24-amino acid peptides are biologically functional proteins $(11,12)$. A rat cDNA encoding a secreted peptide homologous to HN, named Rattin has also been identified, indicating the existence of $\mathrm{HN}$ in other species (13). Indeed, Guo et al. reported that cDNAs identical or similar to the ORF for HN exist in plants, nematodes, rats, mice, and other species (14).

It is hypothesized that $\mathrm{HN}$ is a part of the "retrograde signaling" - a vital communication process between mitochondria and nuclear genome that maintains cellular homeostasis and integrity (15). Very few retrograde signaling molecules and pathways have been identified; including $\mathrm{Ca}^{2+}$, reactive oxygen species (ROS), nitric oxide (NO), carbon monoxide (CO), and cytochrome $c$; and $\mathrm{HN}$ is heralded as the "harbinger" of other mitochondrial-derived peptides by Lee et al. (15).

\section{STRUCTURE OF HN}

Humanin [Sequence: Met-Ala-Pro-Arg-Gly-Phe-Ser-Cys-LeuLeu-Leu-Leu-Thr-Ser-Glu-Ile-Asp-Leu-Pro-Val-Lys-Arg-Arg-Ala (MAPRGFSCLLLLTSEIDLPVKRRA)] is encoded from a $75 \mathrm{bp}$ ORF sequence within the $1,567 \mathrm{bp}$ cDNA, which yields either a 21 or 24-amino acid polypeptide depending on the location of translation machinery. By binding to either intra-cellular molecules [such as insulin-like growth factor-binding protein (IGFBP)-3, Bax, Bak, or tBid] $(14,16-19)$ or membrane receptors $(8,20$, 21), HN promotes cell survival in response to a variety of insults, improves insulin sensitivity, increases glucose stimulated insulin secretion (GSIS), as well as prevents oxidative stress-induced damage due to ischemia/reperfusion (I/R), hypoxia, or starvation (refer to related sections below for references).

Humanin has a positively charged N-terminal (Met-AlaPro-Arg), central hydrophobic region (Gly-Phe-Ser-Cys-Leu-LeuLeu-Leu-Thr-Ser-Glu-Ile-Asp-Leu), and negatively charged Cterminal (Pro-Val-Lys-Arg-Arg-Ala) (1,22). Relatively short structure of $\mathrm{HN}$ has enabled researchers to identify the role of each amino acid residue within the polypeptide through systematic single amino acid substitution technique. Last three residues in the C-terminal are accepted as non-essential because both 21 and 24-amino acid long peptides have indistinguishable intracellular and extracellular effects (22).

Yamagishi et al. postulated that the entire HN peptide functions as a signal peptide for extracellular secretion. They demonstrated that the self-secretory function is lost when any of the amino acid domains within the Leu9-Leu11, or Pro19-Val20 
structure was substituted for Arg (12). Furthermore, Leu10 was identified as having a central role in this process, because Asp substitution of this amino acid (L10A) but not Leu9 or Leu11 completely abolishes the extracellular secretion (12). With regards to the neuro-protective function, Pro3 to Pro19 is termed as "neuro-protective core domain," and the amino acids Pro3, Ser7, Cys8, Leu9, Leu12, Thr13, Ser14, and Pro19 within this domain were found to be essential (12). Single amino acid substitution of these positions to Ala to form P3A, S7A, C8A, L9A, L12A, T13A, S14A, and P19A, respectively, completely abrogates the neuro-protective effect of $\mathrm{HN}$ molecule, whereas, replacement of Ser14 to Gly (S14G, HNG) results in increased cyto-protective potency of HN over 1,000-fold (23). Replacement of Ser14 with $\mathrm{D}$-form Serine (D-Ser) residue also increases neuro-protective function similar to HNG; whereas, D-Ser7 substitution does not (24).

Ikonen et al. demonstrated that Phe6 and Lys21 are essential sites for binding of $\mathrm{HN}$ to its interacting partner, IGFBP-3. While Phe6 to Ala conversion (F6A) completely abolishes the interaction of HN to IGFBP-3, Lys21 to Ala (L21A) conversion blocks the interaction only at lower concentration of IGFBP-3 (16). Combination of the changes at the 6th (F6A) and 14th (S14G) positions creates a more stable, non-IGFBP-3 binding molecule (HNGF6A), which has the ability to modulate insulin action and increase GSIS (25). Recently, Maftei et al. demonstrated that HN (5-15) directly binds to 17-28 region of Amyloid $\beta(\mathrm{A} \beta)(1-40)$ using proteolytic epitope excision and extraction, and affinity-metabolic syndrome (MS) analyses (26). The inhibition of this region of $A \beta$ previously has been shown to effectively decrease aggregation of the neurotoxic amyloid fibrils, and associated cytotoxicity in vitro in human neuroblastoma cell line, SH-SY5Y (27).

Nuclear magnetic resonance (NMR) and circular dichroism (CD) studies have shown that the secondary structure of $\mathrm{HN}$ and HNG is more disordered in water than in PBS, and the different structure in PBS appears to be due to self-association of the peptide (28). The self-association of HN into dimers and/or oligomers appears to occur and seems to be required for biological activities $(12,24)$. A complete list of the function of each amino acid and the effect of substitution are summarized in Table $\mathbf{1}$.

Benaki et al. investigated the structure of synthetic $\mathrm{HN}$ in aqueous and 30\% 2,2,2-trifluoroethanol (TFE) solutions and reported that in aqueous solution, $\mathrm{HN}$ exists predominantly in an unstructured conformation in equilibrium with turn-like structures involving residues Gly5 to Leu10 and Glu15 to Leu18, providing indication of nascent helix (29). In the less polar environment of $30 \%$ TFE, HN readily adopts helical structure with long-range order spanning residues Gly5 to Leu18 (29). Comparative $3 \mathrm{D}$ modeling studies and topology predictions also support the observation. These studies reveal the flexibility of HN molecule in aqueous environment, which makes it free to interact with possible receptors that mediate its action, but also the ability of $\mathrm{HN}$ to acquire a helical conformation necessary for specific interactions and/or passage through membranes (29). Another study showed that HN is readily stabilized in an ordered helical conformation in the TFE/water mixture, but kept partly unfolded in water (30).

\section{HN SIGNALING PATHWAYS}

Humanin exerts its diverse functions through binding to both intracellular molecules and putative cell membrane receptors (Figure 1). Guo et al. demonstrated that $\mathrm{HN}$ binds to Bcl-2associated $\mathrm{X}$ protein (Bax), a pro-apoptotic signaling peptide. Utilizing yeast two-hybrid co-immunoprecipitation studies, the authors demonstrated that wild type $\mathrm{HN}$ specifically binds to inactive form of Bax, inhibits the conformational changes and transfer of Bax from cytosol to the mitochondria, and thereby suppressing cytochrome $c$ release, an initiation step of apoptosis, and inhibiting staurosporine-induced death (14). Another intracellular pro-apoptotic protein " $\mathrm{BH} 3$ interacting-domain death agonist" (Bid), and its truncated form (tBid) were also shown to bind to $\mathrm{HN}$ and contribute to its anti-apoptotic effect (19). Activation of Bid involves proteolytic removal of its $\mathrm{N}$-terminal and myristoylation to form $\mathrm{tBid}$, which then translocates to the mitochondria, leading to the mitochondrial permeabilization and cytochrome $c$ release (31). HN does not block proteolysis of Bid nor prevents the translocation of $\mathrm{tBid}$ to mitochondria, but rather inhibits the association of $\mathrm{tBid}$ with $\mathrm{Bax}$ and as a consequence, prevents tBid-induced oligomerization of Bax, and suppresses release of cytochrome $c$. Furthermore, Ikonen et al. demonstrated that HN binds to and modulates the pro-apoptotic function of IGFBP3 , and regulates cell survival (16). Other intracellular molecules that have been shown to bind to HN are actinin-4 (32), a tripartite motif protein TRIM11 (33), and M-phase phosphoprotein 8 (MPP8) (Figure 1) (34). Recently, a V-set and transmembrane domain containing two like (VSTM2L) protein, was demonstrated to co-localize with $\mathrm{HN}$ in distinct brain areas as well as in primary cultured neurons, and function as an antagonist of $\mathrm{HN}$ (Figure 1) (35).

In terms of the extracellular signaling by $\mathrm{HN}$, Ying et al. reported that $\mathrm{HN}$ induces chemotaxis of human mononuclear phagocytes by binding to human $\mathrm{G}$ protein-coupled formyl peptide receptor-like-1 (FPRL-1) and its murine counterpart FPRL-2 (20). Interestingly, FPRL-1 and FPRL-2 are also functional receptors for Amyloid $\beta$ (A $\beta$ ) 42, an important peptide in the pathophysiology of $\mathrm{AD}$-related neuronal toxicity, suggesting that $\mathrm{HN}$ may exert its neuro-protective effects also by competitively inhibiting the access of FPRL-1 to A $\beta 42$ (20). This hypothesis was further supported by Harada et al. who demonstrated that HN directly binds to FPRL-1 and 2 receptors in Chinese hamster ovary cells expressing the corresponding receptors after transfection (21). On the contrary, Hashimoto et al. showed that HN exerts neuroprotection against $\mathrm{A} \beta$ and activates signal transducer and activator of transcription (STAT) 3 in F11 cells even after siRNA-mediated disruption of FPR2, the mouse counterpart of FPRL-1 (36), suggesting the existence of alternative receptor(s) of HN. In fact, they discovered a tripartite cytokine-like receptor complex [belonging to the interleukin (IL)-6 receptor family] comprising the ciliary neurotrophic factor (CNTF) receptor, the IL-27 receptor WSX1, and glycoprotein (gp)130, activation of which upregulates the Janus Kinase (JAK) 2 and STAT-3 pathways (8). Based on these findings, it is speculated that different cell types express different cell membrane receptors to respond to HN (11). The signaling pathways and binding partners of $\mathrm{HN}$ are summarized in Figure 1. 
Table 1 | Structure of HN peptide and role of individual amino acids.

\begin{tabular}{|c|c|c|c|}
\hline Pos. & Amino acid & Function & Effect of amino acid substitution \\
\hline \multicolumn{4}{|c|}{ N-TERM } \\
\hline 1 & Met (M) & & \\
\hline 2 & Ala $(A)$ & & \\
\hline 3 & Pro (P) & Neuro-protection & Pro3 to Ala (P3A) - abrogates neuro-protective function \\
\hline 4 & $\operatorname{Arg}(\mathbf{R})$ & & \\
\hline \multicolumn{4}{|c|}{ HYDROPHOBIC CORE REGION } \\
\hline 5 & Gly (G) & & \\
\hline 6 & Phe (F) & IGFBP-3 binding, $A \beta$ binding & Phe6 to Ala (F6A) - abrogates IGFBP-3 binding \\
\hline 7 & Ser (S) & $\begin{array}{l}\text { A } \beta \text { protection } \\
A \beta \text { binding } \\
\text { Dimerization }\end{array}$ & $\begin{array}{l}\text { Ser7 to Ala (S7A) - abrogates cyto-protective and } \\
\text { neuro-protective functions, and prevents dimerization }\end{array}$ \\
\hline 8 & Cys (C) & $\begin{array}{l}\text { Neuro-protection } \\
B A X, B A D \text {, and tBID binding }\end{array}$ & Cys8 to Ala (C8A) - abrogates neuro-protective function \\
\hline 9 & Leu (L) & $\begin{array}{l}\text { Neuro-protection } \\
\text { Secretion } \\
\text { Dimerization }\end{array}$ & $\begin{array}{l}\text { Leu9 to Arg (L9R) - Non-secretory, but retains function when } \\
\text { added into the medium } \\
\text { Leu9 Ala (L9A) - prevents dimerization and abrogates } \\
\text { neuro-protective function }\end{array}$ \\
\hline 10 & Leu (L) & Secretion & $\begin{array}{l}\text { Leu10 to Asp (L10D) - abrogates secretion } \\
\text { Leu10 to Arg (L10R) - abrogates secretion }\end{array}$ \\
\hline 11 & Leu (L) & Secretion & Leu11 to Arg (L11R) - abrogates secretion \\
\hline 12 & Leu (L) & Neuro-protection & Leu12 to Ala (L12A) - abrogates neuro-protective function \\
\hline 13 & $\operatorname{Thr}(\mathrm{T})$ & Neuro-protection & Thr13 to Ala (T13A) - abrogates neuro-protective function \\
\hline 14 & Ser (S) & Neuro-protection & $\begin{array}{l}\text { Ser14 to Gly (S14G) increases cyto-protective potency over } \\
\text { 1,000-fold. This isoform is active when monomeric } \\
\text { Ser14 to D-Ser increases potency } \\
\text { Ser14 to Ala (S14A) - abrogates neuro-protective function }\end{array}$ \\
\hline 15 & Glu (E) & & \\
\hline 16 & Ile (I) & & \\
\hline 17 & Asp (D) & & \\
\hline 18 & Leu (L) & & \\
\hline \multicolumn{4}{|c|}{ C-TERM } \\
\hline 19 & Pro (P) & $\begin{array}{l}\text { A } \beta \text { protection } \\
\text { Secretion }\end{array}$ & $\begin{array}{l}\text { Pro19 to Ala (P19A) - abrogates neuro-protective function } \\
\text { Pro19 to Arg (P19R) - abrogates secretion }\end{array}$ \\
\hline 20 & Val (V) & Secretion & Val20 to Arg (V20A) - abrogates secretion \\
\hline 21 & Lys (K) & IGFBP-3 binding & Lys21 to Ala (L21A) - blocks interaction at lower IGFBP-3 \\
\hline 22 & $\operatorname{Arg}(R)$ & ?Non-essential & concentrations \\
\hline 23 & $\operatorname{Arg}(\mathrm{R})$ & ?Non-essential & \\
\hline 24 & Ala $(A)$ & ?Non-essential & \\
\hline
\end{tabular}

Bolded: neuro-protective core domain (NPCD).

Humanin has been shown to activate other signaling pathways besides JAK2-STAT-3, including p38 mitogen-activated protein kinases (p38MAPK) (in human K562 cells, primary rat neurons, and mouse germ cells in vivo) $(37,38)$, AMP-activated protein kinase (AMPK) (mouse cardiac I/R model in vivo) (3), insulin signaling in vivo in mouse models (39-41), and ERK1/2 in vitro (20). It is also reported that $\mathrm{HN}$ inhibits amyloid precursor protein (APP) induced c-Jun N-terminal kinase (JNK) activation and thereby protects neuronal cells from apoptosis (42).

\section{REGULATION OF HN}

The endogenous regulation of $\mathrm{HN}$ under physiological conditions is not yet established. We have shown that the circulating levels of HN decrease with age in both human and mice (43). A relationship between $\mathrm{HN}$ and GH/IGF axis was reported in a recent publication. Long-lived, GH-deficient Ames mice (that have decreased GH and IGF-1) displayed elevated HN levels, while short-lived GH-transgenic mice (high GH and high IGF-1) have reduced HN levels. This relationship was further confirmed in mice and humans; treatment with GH or IGF-1 reduced circulating HN levels (44). Using LID mice (liver specific IGF-1 deletion model-where the GH levels are high, while IGF-1 levels are low) and IGFBP-3 knock-out mice (where free IGF-1 levels are high), the authors demonstrated that the levels of HN are inversely proportional to circulating IGF-1 levels. There is increased expression of $\mathrm{HN}$ in response to $\mathrm{GH}$ 


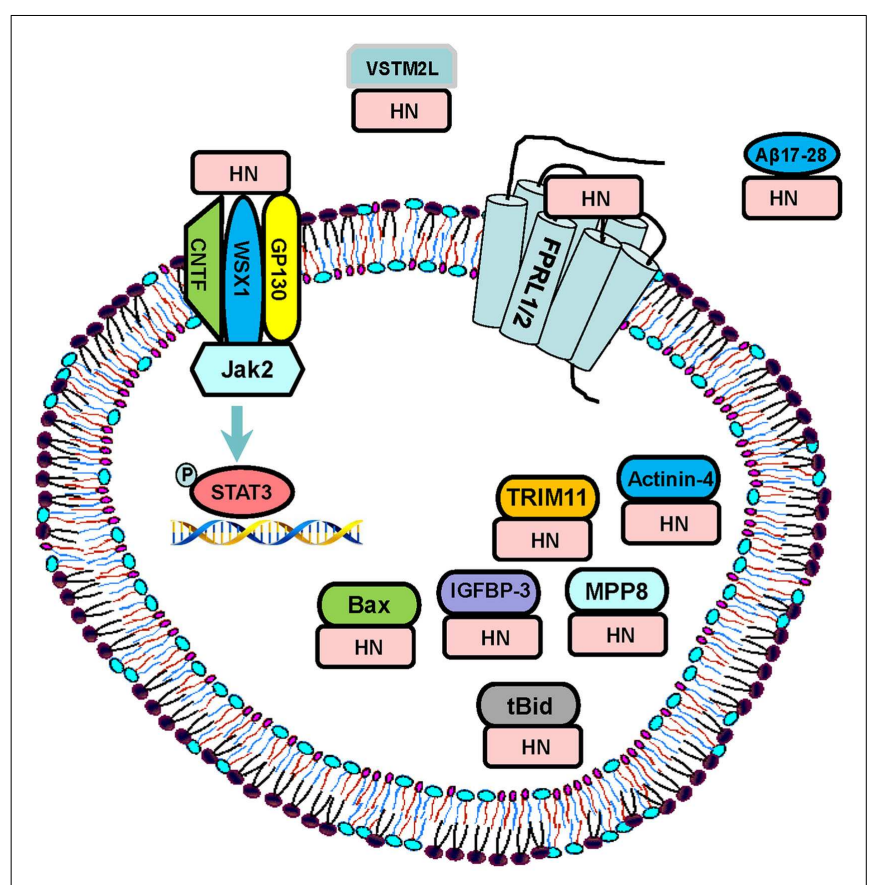

FIGURE 1 | Signaling pathways: HN exerts its function through both extracellular receptors and intracellular binding partners. The proposed extracellular receptors are trimeric receptor complex including CNTF, WSX1, and GP130 and downstream JAK2-STAT-3 signaling pathway, and FPRL-1/2 $G$-protein-coupled receptors. HN directly binds to $A \beta 17-28$ and prevents the interaction of $A \beta 42$ with receptors. $H N$ also binds to its intracellular partners including IGFBP-3, Bax, tBid, MPP8, TRIM11, and actinin-4. VSTM2L is an extracellular antagonist of $\mathrm{HN}$.

and IGF-I in cultured rat Leydig cells between 10 and 40 days of life but not at 2 months of age (6) suggesting a developmental regulation. Niikura et al. identified that $\mathrm{HN}$ interacts with a putative E3 ubiquitin ligase TRIM11, which leads to the degradation of $\mathrm{HN}$ through the proteasome pathway, and regulation of the intracellular level of de novo synthesized HN (33).

Endogenous up-regulation of HN has been demonstrated in certain pathological states. It is shown that HN peptide level is strongly increased in mitochondria and siderosomes in diffusetype of pigmented villonodular synovitis (45). Increase in HN expression is also demonstrated in the muscles of patients with chronic progressive external ophthalmoplegia compared to those in control fibers (5). An increased HN expression level in skeletal muscles from patients with mitochondrial encephalomyopathy with lactic acidosis and stroke-like episodes (MELAS) was also reported (46). The authors suggested that the increase in $\mathrm{HN}$ could be an initial compensation for the defects in energy production in the affected muscle fibers; while further progressive defects may ultimately lead to degenerative ragged-red fibers. Our findings of increased intracellular levels of $\mathrm{HN}$ after myocardial ischemia and reperfusion (MI-R) and persistence as long as $24 \mathrm{~h}$ in mouse cardiac tissue (3) also suggest a compensatory up-regulation of $\mathrm{HN}$ in stress conditions.

\section{ROLE OF HUMANIN IN AGE-RELATED DISEASES}

The discovery of $\mathrm{HN}$ molecule and the demonstration of its neuro-protective activity in $\mathrm{AD}$ inspired researchers from different fields to study the potential role of $\mathrm{HN}$ in the pathophysiology of other neurological and non-neurological diseases (1). To date, $\mathrm{HN}$ and its analogs have been demonstrated to play a role in multiple diseases including type 2 diabetes $(25,43)$, cardiovascular disease (CVD) $(2,3,47)$, memory loss (48), amyotrophic lateral sclerosis (ALS) (49), stroke (50), and inflammation $(22,51)$. The mechanisms that are common to many of these age-related diseases are oxidative stress (52) and mitochondrial dysfunction (53). Mitochondria are major source of ROS, excess of which can cause oxidative damage of cellular lipids, proteins, and DNA. The accumulation of oxidative damage will result in decline of mitochondrial function, which in turn leads to enhanced ROS production (53). This vicious cycle can play a role in cellular damage, apoptosis, and cellular senescence - contributing to aging and age-related diseases. Indeed, oxidative stress is tightly linked to multiple human diseases such as Parkinson's disease (PD) (54), AD (55), atherosclerosis (56), heart failure (57), myocardial infarction (58), chronic inflammation (59), kidney disease (60), stroke (61), cancers $(62,63)$, and many types of metabolic disorders $(64,65)$. We and others have shown that HN plays critical roles in reducing oxidative stress (66-68). In this section, we will summarize the current knowledge on the role of $\mathrm{HN}$ in various age-related diseases.

\section{HN AND NEUROLOGICAL DISEASES \\ ALZHEIMER'S DISEASE}

Alzheimer's disease is predicted to affect 1 in 85 people globally by 2050 . Short-term memory loss and impairment of other cognitive domains are clinical hallmarks of the disease; whereas, cerebral cortical atrophy due to neuronal cell loss particularly in the temporal-parietal lobes, hippocampus and to a lesser extent in the frontal lobes, accumulation of extracellular senile plaques made of amyloid-beta $(A \beta)$ protein (cleavage product of APP), and hyper-phosphorylation of the microtubule associated tau-protein are the main imaging and pathophysiological markers $(25,50)$. The mechanism of the $A \beta$ induced neuronal cell death has not yet fully elucidated; however, multiple groups have postulated the presence of death receptors as the potential mechanism of such insult [for review see Ref. (27)].

Role in $\mathrm{AD}$ has been on the main focus of $\mathrm{HN}$-related research. The effects of $\mathrm{HN}$ on AD-related pathology as well as functional correlates have been tested in in vitro systems and in in vivo mouse models. Hashimoto et al. demonstrated that HN suppresses neuronal cell death induced by $A \beta$ and three different types of familial $\mathrm{AD}$ (FAD) genes including mutant APP, presenilin (PS) 1, and PS2 (1). In addition, $\mathrm{HN}$ inhibits neurotoxicity by $\mathrm{AD}$-relevant insults induced by other FAD genes including A617G-APP, L648P-APP, A246E-PS1, L286V-PS1, C410Y-PS1, and H163R-PS1 and other $A \beta$ peptides ( $A \beta \quad 1-42$ and $A \beta \quad 25-35)$ (1). They showed that HN mediated suppression of the neuronal cell death induced by K595N/M596L-APP (NL-APP) is not through the inhibition of A $\beta 1-42$ secretion but via the HN's inhibitory action on intracellular toxicity triggered by NL-APP and A $\beta$ (69). Furthermore, they showed that secretion is required for the neuro-protective effects 
by using non-secreted biologically active point mutant $\mathrm{HN}$ ana$\log$ (L9R), which is retained in the cytoplasm and did not exert any cyto-protection but was protective when added to the culture medium (1). Tsukamoto et al. demonstrated that $\mathrm{A} \beta$ toxicity in the neuronal cell line can be completely suppressed with $\mathrm{HN}$ via one of the proposed death receptor, the $75-\mathrm{kDa}$ neurotrophin receptor (p75 NTR) (47-49). HN protects PC12 neuronal cells from $\mathrm{A} \beta$-induced viability loss and cell apoptosis, decreases mitochondrial membrane potential and prevents cytochrome $c$ release from mitochondria-key steps in apoptosis (70). A potent $\mathrm{HN}$ analog, $\mathrm{HNG}$, has been shown to not only inhibit the formation of the A $\beta 1-42$ fibrils but also cause disaggregation of the preformed fibrils, which provides novel evidence that HNG may have anti-A $\beta$ aggregation and anti-fibrillogenesis, as well as fibril-destabilizing properties (71).

With intra-cerebro-ventricular (ICV) injection of HNG, A $\beta$ induced impairment of short-term/spatial working memory was prevented in vivo (72). Interestingly, intraperitoneal (IP) administration of HNG also ameliorated behavioral deficits, and reduced neuro-inflammatory responses and apoptosis induced by ICV injection of aggregated $A \beta 25-35$ in mouse brain (73). In a subsequent study, the group showed that chronic treatment (3-month IP injection) of HNG: (i) significantly improves spatial learning and memory deficits, (ii) reduces $A \beta$ plaque accumulation and insoluble $A \beta$ concentrations, and (iii) decreases neuro-inflammatory responses in middle-age APPswe/PS1dE9 mice, a double transgenic mouse model of $\mathrm{AD}$ over expressing APP, and mutant human PS-1 in neurons. Similar pathological and functional improvements were also demonstrated in APPswe, tauP310L, and PS$1 \mathrm{M} 146 \mathrm{~V}$ triple transgenic mice following treatment with HNG. Interestingly, in this model, though there was reduced $\mathrm{A} \beta$ accumulation, no changes in tau phosphorylation levels were noted (74). This suggests that the cyto-protective effect of $\mathrm{HN}$ is independent of the phosphorylation and aggregation of tau-protein. However, more direct and detailed studies are needed to characterize any potential effect of $\mathrm{HN}$ on tau-protein aggregation induced memory loss and learning deficit (75). Novel HN delivery system, using a transducible $\mathrm{HN}$ with an extended caspase- 3 cleavage sequence (tHN-C3), was shown to protect neurons against $\mathrm{H}_{2} \mathrm{O}_{2}$ and soluble $\mathrm{A} \beta 42$ induced cell death in vitro through binding to Bax. Delivering HN through this system was also found to decrease inflammatory cell infiltration, decrease apoptosis in neurons and improve memory learning deficits in genetic ( $\mathrm{Tg} 2576)$ and $\mathrm{A} \beta 42$ induced $\mathrm{AD}$ mouse models, and protect rats from $\mathrm{I} / \mathrm{R}$ induced brain injury (76).

Currently, there is no definitive cure for AD (31). The multiple in vitro and in vivo studies showing that $\mathrm{HN}$ or its potent analogs protect from AD-related neuronal cell death and functional impairments, offer significant promise for a potential role for $\mathrm{HN}$ as a new treatment approach to treat $\mathrm{AD}$.

\section{STROKE}

Stroke [cerebrovascular accident (CVA)] was the second leading cause of death worldwide according to World Health Organization (WHO) report in 2012 (http://who.int/mediacentre/factsheets/ fs310/en/). CVA can be either ischemic or hemorrhagic; ischemic subtype constitutes roughly $80 \%$ of the all strokes (77). The role of $\mathrm{HN}$ has been studied in both ischemic and hemorrhagic types of stroke in mouse models in vivo.

Humanin either alone or in combination with other neuroprotective factors has been shown to offer protection in cerebral $\mathrm{I} / \mathrm{R}$ mice models in vivo. Xu et al. demonstrated that ICV infusion of HNG resulted in smaller infarct volume, decreased number of apoptotic neurons, and improved neurological function in middle cerebral artery occlusion induced I/R injury in mice (50). This was associated with inhibition of ERK (a member of MAPK signaling pathway) phosphorylation and poly (ADP-ribose) polymerase (PARP) activity, a marker of caspase-3 activity (50). Same group also showed that activation of PI3 kinase/Akt signaling pathway is important in HNG's neuro-protective function (40). Furthermore, they also showed that combination of treatment with HNG and a necroptosis inhibitor necrostatin-1 (Nec-1) results in more robust neuro-protection than $\mathrm{HNG}$ or $\mathrm{Nec}-1$ alone on I/R induced cerebral infarct (78). The synergistic effects of HNG and Nec-1 on hypoxia induced neuronal cell death were also replicated in in vitro experiments using cultured mouse primary cortical neurons (78). Others reported that $\mathrm{HN}$ protects cortical neurons from I/R injury through an increase in activity of superoxide dismutase (SOD) (79). Wang et al. showed protective roles of HNG in a mouse model of intracranial hemorrhage following IP administration within 1 hour post injury (41); treatment with HNG resulted in decreased brain edema, neuronal cell death, and injury volume while improving neurological recovery.

The results of the limited studies are promising; however, more studies are needed to better understand if $\mathrm{HN}$ can be used as a therapeutic agent in the management of CVA.

\section{OTHER NEUROLOGICAL CONDITIONS}

Humanin was shown to play role in certain other neurological diseases. HN was found to offer protective effect from Prionpeptide (PrP) (118-135)-induced cell death, but not against $\operatorname{PrP}$ (106-126). The reason for this selective protection is not clear though the mechanistic differences between these two PrPs inducing apoptosis could be a contributor (80). Mamiya et al. evaluated the effects of the scopolamine-HBr induced impairment of spontaneous alternation behavior in mice using the Y-maze as an index of short-term memory, and found that HNG reversed the anti-cholinergic drug mediated impairment of the learning and memory function in mice (48). In a recent publication, Cui et al. reported that $\mathrm{HN}$ rescued cortical neurons from excitatory toxicity caused by NMDA in a dose-dependent manner without interacting with the receptors, and pointed to the potential role of its use in preventing the damage caused by this pathway (81). However, studies have shown that $\mathrm{HN}$ failed to protect against certain cytotoxicity including Q79, SOD mutants, etoposide, Fas, or basally occurring death indicating specificity in action (1).

\section{HN AND CARDIOVASCULAR DISEASES}

Cardiovascular disease is the number one leading cause of death in the United States and worldwide (82). Aging is the biggest risk factor for the development of CVDs; risk approximately triples with each decade of life (83). American Heart Association statistics report in 2006 states that $88 \%$ of people who died of coronary heart disease were 65 and older (84). 
We and others have shown that heart expresses the highest level of $\mathrm{HN}$ at both mRNA and protein levels $(3,13,67)$. HN is expressed in the endothelial cell lining of the coronary arteries, human internal mammary arteries, and sections of the greater saphenous vein as demonstrated by immune-staining (67). Endogenous HN levels increase after myocardial I/R in mice, and $\mathrm{HN}$ is present in the atherosclerotic plaques of the coronary arteries suggesting a role for $\mathrm{HN}$ in cardiovascular health.

When HNG is administered exogenously, either pre-ischemia or at the time of reperfusion in a mouse model of myocardial $\mathrm{I} / \mathrm{R}$, there is a dose-dependent decrease in infarct size (3). In addition, HNG treated mice demonstrated better cardiac function post MI-R as demonstrated by improved ejection fraction, end-systolic volume and end-diastolic volume, and cardiac output (3). Furthermore, we also observed that HNG protects cardiac myoblasts from oxidative stress-induced cell death by acutely increasing activity of antioxidants through involvement of non-receptor tyrosine kinases (66).

Widmer et al. reported that human coronary endothelial function dysfunction is associated with lower systemic HN levels, introducing a potential diagnostic and/or therapeutic target for patients with coronary endothelial dysfunction (9). The same group also demonstrated that the treatment with exogenous $\mathrm{HN}$ protected endothelial cell cultures from Ox-LDL-induced oxidative stress and apoptosis (67). Daily IP injection of HNGF6A for 16 weeks prevented endothelial dysfunction and decreased atherosclerotic plaque size in the proximal aorta of Apo-E deficient mice fed with a high-cholesterol diet, attributable to the reduction in apoptosis rate and preservation of eNOS activity (68). In the same mouse model, it was shown that $\mathrm{HN}$ attenuates renal microvascular remodeling, inflammation, and apoptosis in the early stage of kidney disease, indicating that HN may serve as a novel therapeutic target to mitigate kidney damage in early atherosclerosis (2). HN was also demonstrated in the carotid atherosclerotic plaques in humans, and the expression level of $\mathrm{HN}$ was found to be inversely correlated with the stability of the plaques, i.e., more HN was present in unstable plaques and patients from stroke subgroup (47). Whether this suggests a direct role of $\mathrm{HN}$ in the formation or stability of the carotid atherosclerotic plaques needs to be established.

\section{HN AND METABOLIC EFFECTS}

T2DM is one of the most common metabolic diseases and its prevalence directly correlates with increasing age, peaking at 6074. Almost one-third of the elderly have diabetes and three quarters have diabetes or pre-diabetes (85-87). Age associated changes in hormonal milieu along with changes in body composition contribute to insulin resistance and increased incidence of diabetes. In addition, aging is associated with decreased beta-cell proliferative capacity and enhanced sensitivity to apoptosis (88). Both peripheral insulin resistance and impaired insulin secretion contribute to the pathogenesis of T2DM in aging $(86,89)$.

Role of $\mathrm{HN}$ in glucose homeostasis has been studied using hyperinsulinemic-euglycemic clamp and hyperglycemic clamp techniques. Hyperinsulinemic-euglycemic clamp is the gold standard method to assess in vivo insulin sensitivity and allows assessment of insulin sensitivity specifically at the level of liver and muscle. During hyperinsulinemic-euglycemic clamps, rats receiving continuous ICV infusion of $\mathrm{HN}$ required higher glucose infusion rate (GIR) to maintain normoglycemia as a result of decreased hepatic glucose output and increased glucose uptake in the skeletal muscle, demonstrating increased insulin sensitivity. The central action of HN was shown to be mediated via activation of hypothalamic STAT-3 signaling pathway (43). Our group also demonstrated that continuous IV infusion of HNGF6A, $\mathrm{HN}$ analog that is stable, potent, and non-IGFBP-3 binding, during hyperinsulinemic-euglycemic clamp increased GIR, peripheral glucose uptake, and suppressed hepatic glucose production. Moreover, HNGF6A, when given as a single IV injection, significantly lowered the blood glucose in Zucker diabetic fatty rats (43). In addition, we showed that $\mathrm{HN}$ increases glucose uptake into the $\beta$ cells, enhances glucose oxidation resulting in an increased GSIS as demonstrated in vivo, in cultured beta cells and in islets isolated from wild type and diabetic mice (25). These studies indicate a role for $\mathrm{HN}$ in whole body glucose homeostasis through both improved insulin action and increased insulin secretion.

Non-obese diabetic mouse is an autoimmune model for T1DM; the development of diabetes is time-dependent as age correlates with increased lymphocyte infiltration, decreased beta-cell proliferation, and enhanced sensitivity to glucose-induced $\beta$-cell apoptosis (88). Treating non-obese diabetic (NOD) mice with HN for 6 weeks normalized glucose tolerance and treatment for 20 weeks prevented/delayed the onset of diabetes in these mice, secondary to decreased lymphocyte infiltration in the islets and decreased apoptosis.

Humanin expression is increased in small arteries along with succinate dehydrogenase positive staining in MELAS muscle fibers, and synthesized HN increases cellular ATP levels by directly acting on mitochondria in TE671, a human rhabdomyosarcoma cell line (46). We also reported that HNGF6A increases mitochondria metabolism and ATP generation in the cultured $\beta$ cells (25) showing a role for $\mathrm{HN}$ in substrate metabolism.

The prevalence of MS also increases with age (90). MS, polycystic ovarian syndrome, non-alcoholic fatty liver disease, and dyslipidemia are closely associated with insulin resistance $(91,92)$. A future direction would be to determine whether $\mathrm{HN}$ has a role in the pathophysiology of these diseases.

\section{HN AND INFLAMMATION}

Obesity, CVD, diabetes, chronic kidney disease, and $\mathrm{AD}$ are associated with a chronic inflammatory state (87, 93-95). Aging per se is characterized by chronic low-grade systemic inflammation even in the absence of chronic disease, as the circulating levels of pro-inflammatory cytokines such as IL-6, tumor necrosis factor (TNF)- $\alpha$, and acute phase proteins such as C-reactive protein (CRP) and serum amyloid A (SAA) increase by two to fourfold in elderly (96). Chronic inflammation in the elderly may contribute to multiple diseases, poor physical functioning, and mortality (97). Therefore, reversing the process of chronic inflammation or, at least, slowing it down has been an attractive area of research in an effort to prevent or delay morbidities/mortalities associated with these conditions.

A role for $\mathrm{HN}$ in down-regulation of inflammatory responses has been demonstrated in vivo and in cell culture systems. 
Miao et al. first observed that HNG ameliorates A $325-35-$ induced neuro-inflammatory responses by decreasing the level of IL- 6 and TNF- $\alpha$ in mice (73). This important finding may suggest that in addition to exerting functions through binding to membrane receptors and intra-cellular molecules, HNG also offers neuro-protection in $\mathrm{AD}$ by altering the inflammatory response. Zhang and colleagues discovered that $\mathrm{HN}$ attenuates inflammation by down-regulating intra-renal inflammatory markers of MCP-1, TNF- $\alpha$, and osteopontin and reduces macrophage infiltration in hypercholesterolemic Apo-E deficient mice; thereby decreasing the renal microvascular remodeling, inflammation, and apoptosis in the early stage of kidney disease (2). Finally, Zhao et al. reported that treatment of HNG partially suppresses the secretion of proinflammatory cytokines including IL-6, IL- $1 \beta$, and TNF- $\alpha$ in a dose-dependent manner in astrocytes induced by lipopolysaccharides (LPS) (51).

\section{HN AND CANCERS}

Age-related increase in cancer risk, with leveling off at advanced ages is well-established (98). HN's well-known anti-apoptotic property raised concern among the researchers whether HN contributes to cancer development and helps cancer cell survival. Maximov et al. hypothesized that $\mathrm{HN}$ is an oncopeptide (99), based on the finding of up-regulation of expression of the mitochondrial 16S rRNA gene in non-Hodgkin's lymphoma, which potentially enhances $\mathrm{HN}$ expression. Furthermore, HN was immunologically detected in the serum of some patients with cutaneous T-cell lymphoma but not in healthy subjects (100). Using the yeast twohybrid model, the Maximov group identified MPP8 as a binding partner for HN (101), which is a previously described oncoprotein playing a role in tumor motility and invasion (101); and thus pointing to the potential role of $\mathrm{HN}$ in oncogenesis. Recently, a suppression subtractive hybridization study showed the overexpression of $\mathrm{HN}$ and isoforms in chemo-resistant tumor gastric tissues from patients. Utilizing qRT-PCR, the authors confirmed the increased mRNA levels of HN1, HN3, HN6, and HN10 genes, suggesting potential role of $\mathrm{HN}$ in the development of chemoresistance in gastric tumor cells. The limitation of the study, as noted by the authors, was the lack of protein level measurements that could not be performed due to lack of isoform-specific antibodies.

Contrary to the potential role of $\mathrm{HN}$ in tumorigenesis and metastasis of the cancer cells, Eriksson and colleagues demonstrated that, when HNG is administered with bortezomib [proteasome inhibitor currently studied in clinical trials of childhood leukemia and other cancers that induces apoptosis in growth plate chondrocytes and impair linear bone growth in treated mice (102107)], HNG prevented bortezomib-induced bone growth impairment in mice with human tumor xenograft models (108), without affecting its chemotherapeutic effects. They also showed in human tumor xenograft and cell lines that HNG prevented bortezomibinduced apoptosis by preventing Bax and PARP activation (108). More interestingly, HNG alone delayed tumor growth and tumor doubling time in cancers such as medulloblastoma and neuroblastoma in vivo (108). The authors speculated that increased Bax in chondrocytes compared to human neuroblastoma cells could be the basis for chondrocyte-rescuing effect of HNG following bortezomib treatment.

The current data on the relationship between HN, tumorigenesis, and cancer metastasis are not conclusive. More studies are needed to understand if the changes in expression of $\mathrm{HN}$ are tumor-type specific, whether they are a cause or a compensatory response and if they affect the response to treatment.

\section{PERSPECTIVE}

Since its discovery, $\mathrm{HN}$ has been demonstrated to offer beneficial effects in many diseases, many of which are age-related. The observation that levels of $\mathrm{HN}$ decline with age further supports the role of $\mathrm{HN}$ in aging and age-related diseases. Diseases which were earlier considered age-related such as T2DM are now seen in much younger ages due to the burgeoning epidemic of obesity. The role of $\mathrm{HN}$ in mitigating the effects of bortezomib on growth plate chondrocyte apoptosis and islet cell apoptosis on autoimmune mouse model of diabetes extend the potential role of $\mathrm{HN}$ beyond the spectrum of age-related diseases. $\mathrm{HN}$ and analogs offer promise as a potential therapeutic option for neurodegenerative disorders, CVDs, diabetes, and a potential adjunct to chemotherapy. Further studies are needed to evaluate the pharmacokinetics and safety profile for long term use. Gain and loss of function models are necessary to fill the gaps in our current knowledge and enhance our understanding of the physiological role of this peptide and its role in various diseases.

\section{REFERENCES}

1. Hashimoto Y, Niikura T, Tajima H, Yasukawa T, Sudo H, Ito Y, et al. A rescue factor abolishing neuronal cell death by a wide spectrum of familial Alzheimer's disease genes and Abeta. Proc Natl Acad Sci U S A (2001) 98:6336-41. doi:10.1073/pnas.101133498

2. Zhang X, Urbieta-Caceres VH, Eirin A, Bell CC, Crane JA, Tang H, et al. Humanin prevents intra-renal microvascular remodeling and inflammation in hypercholesterolemic ApoE deficient mice. Life Sci (2012) 91:199-206. doi:10.1016/j.lfs.2012.07.010

3. Muzumdar RH, Huffman DM, Calvert JW, Jha S, Weinberg Y, Cui L, et al. Acute humanin therapy attenuates myocardial ischemia and reperfusion injury in mice. Arterioscler Thromb Vasc Biol (2010) 30:1940-8. doi:10.1161/ATVBAHA. 110.205997

4. Moretti E, Giannerini V, Rossini L, Matsuoka M, Trabalzini L, Collodel G. Immunolocalization of humanin in human sperm and testis. Fertil Steril (2010) 94:2888-90. doi:10.1016/j.fertnstert.2010.04.075

5. Brookmeyer R, Gray S, Kawas C. Projections of Alzheimer's disease in the United States and the public health impact of delaying disease onset. Am J Public Health (1998) 88:1337-42. doi:10.2105/AJPH.88.9.1337

6. Colon E, Strand ML, Carlsson-Skwirut C, Wahlgren A, Svechnikov KV, Cohen $\mathrm{P}$, et al. Anti-apoptotic factor humanin is expressed in the testis and prevents cell-death in Leydig cells during the first wave of spermatogenesis. J Cell Physiol (2006) 208:373-85. doi:10.1002/jcp.20672

7. Chin YP, Keni J, Wan J, Mehta H, Anene F, Jia Y, et al. Pharmacokinetics and tissue distribution of humanin and its analogues in male rodents. Endocrinology (2013) 154:3739-44. doi:10.1210/en.2012-2004

8. Hashimoto Y, Kurita M, Aiso S, Nishimoto I, Matsuoka M. Humanin inhibits neuronal cell death by interacting with a cytokine receptor complex or complexes involving CNTF receptor alpha/WSX-1/gp130. Mol Biol Cell (2009) 20:2864-73. doi:10.1091/mbc.E09-02-0168

9. Widmer RJ, Flammer AJ, Herrmann J, Rodriguez-Porcel M, Wan J, Cohen $\mathrm{P}$, et al. Circulating humanin levels are associated with preserved coronary endothelial function. Am J Physiol Heart Circ Physiol (2013) 304:H393-7. doi:10.1152/ajpheart.00765.2012

10. Tajima H, Niikura T, Hashimoto Y, Ito Y, Kita Y, Terashita K, et al. Evidence for in vivo production of humanin peptide, a neuroprotective factor 
against Alzheimer's disease-related insults. Neurosci Lett (2002) 324:227-31. doi:10.1016/S0304-3940(02)00199-4

11. Yen K, Lee C, Mehta H, Cohen P. The emerging role of the mitochondrialderived peptide humanin in stress resistance. J Mol Endocrinol (2013) 50:R11-9. doi:10.1530/JME-12-0203

12. Yamagishi Y, Hashimoto Y, Niikura T, Nishimoto I. Identification of essential amino acids in Humanin, a neuroprotective factor against Alzheimer's diseaserelevant insults. Peptides (2003) 24:585-95. doi:10.1016/S0196-9781(03) 00106-2

13. Caricasole A, Bruno V, Cappuccio I, Melchiorri D, Copani A, Nicoletti F. A novel rat gene encoding a Humanin-like peptide endowed with broad neuroprotective activity. FASEB J (2002) 16(10):1331-3. doi:10.1096/fj.02-0018fje

14. Guo B, Zhai D, Cabezas E, Welsh K, Nouraini S, Satterthwait AC, et al. Humanin peptide suppresses apoptosis by interfering with Bax activation. Nature (2003) 423:456-61. doi:10.1038/nature01627

15. Lee C, Yen K, Cohen P. Humanin: a harbinger of mitochondrial-derived peptides? Trends Endocrinol Metab (2013) 24:222-8. doi:10.1016/j.tem.2013.01. 005

16. Ikonen M, Liu B, Hashimoto Y, Ma L, Lee KW, Niikura T, et al. Interaction between the Alzheimer's survival peptide humanin and insulin-like growth factor-binding protein 3 regulates cell survival and apoptosis. Proc Natl Acad Sci U S A (2003) 100:13042-7. doi:10.1073/pnas.2135111100

17. Luciano F, Zhai D, Zhu X, Bailly-Maitre B, Ricci JE, Satterthwait AC, et al. Cytoprotective peptide humanin binds and inhibits proapoptotic Bcl-2/Bax family protein BimEL. J Biol Chem (2005) 280:15825-35. doi:10.1074/jbc. M413062200

18. Muzumdar RH, Ma X, Fishman S, Yang X, Atzmon G, Vuguin P, et al. Central and opposing effects of IGF-I and IGF-binding protein-3 on systemic insulin action. Diabetes (2006) 55:2788-96. doi:10.2337/db06-0318

19. Zhai D, Luciano F, Zhu X, Guo B, Satterthwait AC, Reed JC. Humanin binds and nullifies Bid activity by blocking its activation of Bax and Bak. J Biol Chem (2005) 280:15815-24. doi:10.1074/jbc.M411902200

20. Ying G, Iribarren P, Zhou Y, Gong W, Zhang N, Yu ZX, et al. Humanin, a newly identified neuroprotective factor, uses the $G$ protein-coupled formylpeptide receptor-like-1 as a functional receptor. J Immunol (2004) 172:7078-85. doi:10.4049/jimmunol.172.11.7078

21. Harada M, Habata Y, Hosoya M, Nishi K, Fujii R, Kobayashi M, et al. NFormylated humanin activates both formyl peptide receptor-like 1 and 2 . Biochem Biophys Res Commun (2004) 324:255-61. doi:10.1016/j.bbrc.2004.09. 046

22. Zapala B, Kaczynski L, Kiec-Wilk B, Staszel T, Knapp A, Thoresen GH, et al. Humanins, the neuroprotective and cytoprotective peptides with antiapoptotic and anti-inflammatory properties. Pharmacol Rep (2010) 62:767-77. doi:10.1016/S1734-1140(10)70337-6

23. Alonso A, Zaidi T, Novak M, Grundke-Iqbal I, Iqbal K. Hyperphosphorylation induces self-assembly of tau into tangles of paired helical filaments/straight filaments. Proc Natl Acad Sci U S A (2001) 98:6923-8. doi:10.1073/pnas. 121119298

24. Terashita K, Hashimoto Y, Niikura T, Tajima H, Yamagishi Y, Ishizaka $\mathrm{M}$, et al. Two serine residues distinctly regulate the rescue function of Humanin, an inhibiting factor of Alzheimer's disease-related neurotoxicity: functional potentiation by isomerization and dimerization. J Neurochem (2003) 85:1521-38. doi:10.1046/j.1471-4159.2003.01797.x

25. Kuliawat R, Klein L, Gong Z, Nicoletta-Gentile M, Nemkal A, Cui L, et al. Potent humanin analog increases glucose-stimulated insulin secretion through enhanced metabolism in the beta cell. FASEB J (2013) 27:4890-8. doi:10.1096/ fj.13-231092

26. Maftei M, Tian X, Manea M, Exner TE, Schwanzar D, von Arnim CA, et al. Interaction structure of the complex between neuroprotective factor humanin and Alzheimer's beta-amyloid peptide revealed by affinity mass spectrometry and molecular modeling. J Pept Sci (2012) 18:373-82. doi:10.1002/psc.2404

27. Kawasumi M, Hashimoto Y, Chiba T, Kanekura K, Yamagishi Y, Ishizaka $\mathrm{M}$, et al. Molecular mechanisms for neuronal cell death by Alzheimer's amyloid precursor protein-relevant insults. Neurosignals (2002) 11:236-50. doi:10.1159/000067424

28. Arakawa T, Niikura T, Tajima H, Kita Y. The secondary structure analysis of a potent Ser 14Gly analog of antiAlzheimer peptide, humanin, by circular dichroism. J Pept Sci (2006) 12:639-42. doi:10.1002/psc.773
29. Benaki D, Zikos C, Evangelou A, Livaniou E, Vlassi M, Mikros E, et al. Solution structure of humanin, a peptide against Alzheimer's disease-related neurotoxicity. Biochem Biophys Res Commun (2005) 329:152-60. doi:10.1016/j.bbrc. 2005.01.100

30. Mehrnejad F, Chaparzadeh N. Structural and dynamical studies of Humanin in water and TFE/water mixture: a molecular dynamics simulation. J Biomol Struct Dyn (2008) 26:255-62. doi:10.1080/07391102.2008.10507241

31. Brookmeyer R, Johnson E, Ziegler-Graham K, Arrighi HM. Forecasting the global burden of Alzheimer's disease. Alzheimers Dement (2007) 3:186-91. doi:10.1016/j.jalz.2007.04.381

32. Kigawa A, Wakui H, Maki N, Okuyama S, Masai R, Ohtani H, et al. Interaction of the spectrin-like repeats of alpha-actinin-4 with humanin peptide. Clin Exp Nephrol (2004) 8:331-8. doi:10.1007/s10157-004-0322-y

33. Niikura T, Hashimoto Y, Tajima H, Ishizaka M, Yamagishi Y, Kawasumi M, et al. A tripartite motif protein TRIM11 binds and destabilizes Humanin, a neuroprotective peptide against Alzheimer's disease-relevant insults. Eur J Neurosci (2003) 17:1150-8. doi:10.1046/j.1460-9568.2003.02553.x

34. Maximov VV, Martynenko AV, Arman IP, Tarantul VZ. Humanin binds MPP8: mapping interaction sites of the peptide and protein. JPept Sci (2013) 19:301-7. doi: $10.1002 /$ psc. 2500

35. Rossini L, Hashimoto Y, Suzuki H, Kurita M, Gianfriddo M, Scali C, et al. VSTM2L is a novel secreted antagonist of the neuroprotective peptide Humanin. FASEB J (2011) 25:1983-2000. doi:10.1096/fj.10-163535

36. Hashimoto Y, Suzuki H, Aiso S, Niikura T, Nishimoto I, Matsuoka M. Involvement of tyrosine kinases and STAT3 in Humanin-mediated neuroprotection. Life Sci (2005) 77:3092-104. doi:10.1016/j.lfs.2005.03.031

37. Wang D, Li H, Yuan H, Zheng M, Bai C, Chen L, et al. Humanin delays apoptosis in K562 cells by downregulation of P38 MAP kinase. Apoptosis (2005) 10:963-71. doi:10.1007/s10495-005-1191-x

38. Niikura T, Yamada M, Chiba T, Aiso S, Matsuoka M, Nishimoto I. Characterization of V642I-AbetaPP-induced cytotoxicity in primary neurons. J Neurosci Res (2004) 77:54-62. doi:10.1002/jnr.20139

39. Singh BK, Mascarenhas DD. Bioactive peptides control receptor for advanced glycated end product-induced elevation of kidney insulin receptor substrate 2 and reduce albuminuria in diabetic mice. Am J Nephrol (2008) 28:890-9. doi:10.1159/000141042

40. Xu X, Chua CC, Gao J, Chua KW, Wang H, Hamdy RC, et al. Neuroprotective effect of humanin on cerebral ischemia/reperfusion injury is mediated by a PI3K/Akt pathway. Brain Res (2008) 1227:12-8. doi:10.1016/j.brainres.2008. 06.018

41. Wang T, Huang Y, Zhang M, Wang L, Wang Y, Zhang L, et al. [Gly14]-Humanin offers neuroprotection through glycogen synthase kinase-3beta inhibition in a mouse model of intracerebral hemorrhage. Behav Brain Res (2013) 247:132-9. doi:10.1016/j.bbr.2013.03.023

42. Hashimoto Y, Tsuji O, Niikura T, Yamagishi Y, Ishizaka M, Kawasumi M, et al. Involvement of c-Jun N-terminal kinase in amyloid precursor proteinmediated neuronal cell death. J Neurochem (2003) 84:864-77. doi:10.1046/j. 1471-4159.2003.01585.x

43. Muzumdar RH, Huffman DM, Atzmon G, Buettner C, Cobb LJ, Fishman S, et al. Humanin: a novel central regulator of peripheral insulin action. PLoS One (2009) 4:e6334. doi:10.1371/journal.pone.0006334

44. Lee C, Wan J, Miyazaki B, Fang Y, Guevara-Aguirre J, Yen K, et al. IGF-I regulates the age-dependent signaling peptide humanin. Aging Cell (2014) 13(5):958-61. doi:10.1111/acel.12243

45. Hashimoto Y, Terashita K, Niikura T, Yamagishi Y, Ishizaka M, Kanekura $\mathrm{K}$, et al. Humanin antagonists: mutants that interfere with dimerization inhibit neuroprotection by Humanin. Eur J Neurosci (2004) 19:2356-64. doi:10.1111/j.0953-816X.2004.03298.x

46. Kariya S, Hirano M, Furiya Y, Sugie K, Ueno S. Humanin detected in skeletal muscles of MELAS patients: a possible new therapeutic agent. Acta Neuropathol (2005) 109:367-72. doi:10.1007/s00401-004-0965-5

47. Zacharias DG, Kim SG, Massat AE, Bachar AR, Oh YK, Herrmann J, et al. Humanin, a cytoprotective peptide, is expressed in carotid atherosclerotic [corrected] plaques in humans. PLoS One (2012) 7:e31065. doi:10.1371/journal. pone.0031065

48. Mamiya T, Ukai M. [Gly(14)]-Humanin improved the learning and memory impairment induced by scopolamine in vivo. Br J Pharmacol (2001) 134:1597-9. doi:10.1038/sj.bjp.0704429 
49. Matsuoka M, Hashimoto Y, Aiso S, Nishimoto I. Humanin and colivelin: neuronal-death-suppressing peptides for Alzheimer's disease and amyotrophic lateral sclerosis. CNS Drug Rev (2006) 12:113-22. doi:10.1111/j.1527-3458. 2006.00113.x

50. Xu X, Chua CC, Gao J, Hamdy RC, Chua BH. Humanin is a novel neuroprotective agent against stroke. Stroke (2006) 37:2613-9. doi:10.1161/01.STR. $0000242772.94277 .1 \mathrm{f}$

51. Zhao ST, Zhao L, Li JH. Neuroprotective Peptide humanin inhibits inflammatory response in astrocytes induced by lipopolysaccharide. Neurochem Res (2013) 38:581-8. doi:10.1007/s11064-012-0951-6

52. Dai DF, Chiao YA, Marcinek DJ, Szeto HH, Rabinovitch PS. Mitochondrial oxidative stress in aging and healthspan. Longev Healthspan (2014) 3:6. doi:10.1186/2046-2395-3-6

53. Cui H, Kong Y, Zhang H. Oxidative stress, mitochondrial dysfunction, and aging. J Signal Transduct (2012) 2012:646354. doi:10.1155/2012/646354

54. Jenner P. Oxidative stress in Parkinson's disease. Ann Neurol (2003) 53(Suppl 3):S26-36. doi:10.1002/ana.10483

55. Markesbery WR. Oxidative stress hypothesis in Alzheimer's disease. Free Radic Biol Med (1997) 23:134-47. doi:10.1016/S0891-5849(96)00629-6

56. Singh U, Jialal I. Oxidative stress and atherosclerosis. Pathophysiology (2006) 13:129-42. doi:10.1016/j.pathophys.2006.05.002

57. Tsutsui H, Kinugawa S, Matsushima S. Oxidative stress and heart failure. Am J Physiol Heart Circ Physiol (2011) 301:H2181-90. doi:10.1152/ajpheart.00554. 2011

58. Di Filippo C, Cuzzocrea S, Rossi F, Marfella R, D’Amico M. Oxidative stress as the leading cause of acute myocardial infarction in diabetics. Cardiovasc Drug Rev (2006) 24:77-87. doi:10.1111/j.1527-3466.2006.00077.x

59. Federico A, Morgillo F, Tuccillo C, Ciardiello F, Loguercio C. Chronic inflammation and oxidative stress in human carcinogenesis. Int J Cancer (2007) 121:2381-6. doi:10.1002/ijc. 23192

60. Ozbek E. Induction of oxidative stress in kidney. Int J Nephrol (2012) 2012:465897. doi:10.1155/2012/465897

61. Allen CL, Bayraktutan U. Oxidative stress and its role in the pathogenesis of ischaemic stroke. Int J Stroke (2009) 4:461-70. doi:10.1111/j.1747-4949.2009. 00387.x

62. Sosa V, Moline T, Somoza R, Paciucci R, Kondoh H, ME LL. Oxidative stress and cancer: an overview. Ageing Res Rev (2013) 12:376-90. doi:10.1016/j.arr. 2012.10.004

63. Fiaschi T, Chiarugi P. Oxidative stress, tumor microenvironment, and metabolic reprogramming: a diabolic liaison. Int J Cell Biol (2012) 2012:762825. doi:10.1155/2012/762825

64. Roberts CK, Sindhu KK. Oxidative stress and metabolic syndrome. Life Sci (2009) 84:705-12. doi:10.1016/j.lfs.2009.02.026

65. Furukawa S, Fujita T, Shimabukuro M, Iwaki M, Yamada Y, Nakajima Y, et al. Increased oxidative stress in obesity and its impact on metabolic syndrome. $J$ Clin Invest (2004) 114:1752-61. doi:10.1172/JCI21625

66. Klein LE, Cui L, Gong Z, Su K, Muzumdar R. A humanin analog decreases oxidative stress and preserves mitochondrial integrity in cardiac myoblasts. Biochem Biophys Res Commun (2013) 440:197-203. doi:10.1016/j.bbrc.2013. 08.055

67. Bachar AR, Scheffer L, Schroeder AS, Nakamura HK, Cobb LJ, Oh YK, et al. Humanin is expressed in human vascular walls and has a cytoprotective effect against oxidized LDL-induced oxidative stress. Cardiovasc Res (2010) 88:360-6. doi:10.1093/cvr/cvq191

68. Oh YK, Bachar AR, Zacharias DG, Kim SG, Wan J, Cobb LJ, et al. Humanin preserves endothelial function and prevents atherosclerotic plaque progression in hypercholesterolemic ApoE deficient mice. Atherosclerosis (2011) 219:65-73. doi:10.1016/j.atherosclerosis.2011.06.038

69. Hashimoto Y, Ito Y, Niikura T, Shao Z, Hata M, Oyama F, et al. Mechanisms of neuroprotection by a novel rescue factor humanin from Swedish mutant amyloid precursor protein. Biochem Biophys Res Commun (2001) 283:460-8. doi:10.1006/bbrc.2001.4765

70. Jin H, Liu T, Wang WX, Xu JH, Yang PB, Lu HX, et al. Protective effects of [Gly14]-Humanin on beta-amyloid-induced PC12 cell death by preventing mitochondrial dysfunction. Neurochem Int (2010) 56:417-23. doi:10.1016/j. neuint.2009.11.015

71. Zhang W, Du Y, Bai M, Xi Y, Li Z, Miao J. S14G-humanin inhibits Abeta142 fibril formation, disaggregates preformed fibrils, and protects against
Abeta-induced cytotoxicity in vitro. J Pept Sci (2013) 19:159-65. doi:10.1002/ psc. 2484

72. Tajima H, Kawasumi M, Chiba T, Yamada M, Yamashita K, Nawa M, et al. A humanin derivative, S14G-HN, prevents amyloid-beta-induced memory impairment in mice. J Neurosci Res (2005) 79:714-23. doi:10.1002/jnr. 20391

73. Miao J, Zhang W, Yin R, Liu R, Su C, Lei G, et al. S14G-Humanin ameliorates Abeta25-35-induced behavioral deficits by reducing neuroinflammatory responses and apoptosis in mice. Neuropeptides (2008) 42:557-67. doi:10.1016/j.npep.2008.08.004

74. Niikura T, Sidahmed E, Hirata-Fukae C, Aisen PS, Matsuoka Y. A humanin derivative reduces amyloid beta accumulation and ameliorates memory deficit in triple transgenic mice. PLoS One (2011) 6:e16259. doi:10.1371/journal.pone. 0016259

75. Zhang W, Zhang W, Li Z, Hao J, Zhang Z, Liu L, et al. S14G-humanin improves cognitive deficits and reduces amyloid pathology in the middleaged APPswe/PS1dE9 mice. Pharmacol Biochem Behav (2012) 100:361-9. doi:10.1016/j.pbb.2011.09.012

76. Park TY, Kim SH, Shin YC, Lee NH, Lee RK, Shim JH, et al. Amelioration of neurodegenerative diseases by cell death-induced cytoplasmic delivery of humanin. J Control Release (2013) 166:307-15. doi:10.1016/j.jconrel.2012.12.022

77. Donnan GA, Fisher M, Macleod M, Davis SM. Stroke. Lancet (2008) 371:1612-23. doi:10.1016/S0140-6736(08)60694-7

78. Xu X, Chua KW, Chua CC, Liu CF, Hamdy RC, Chua BH. Synergistic protective effects of humanin and necrostatin-1 on hypoxia and ischemia/reperfusion injury. Brain Res (2010) 1355:189-94. doi:10.1016/j. brainres.2010.07.080

79. Zhao ST, Huang XT, Zhang C, Ke Y. Humanin protects cortical neurons from ischemia and reperfusion injury by the increased activity of superoxide dismutase. Neurochem Res (2012) 37:153-60. doi:10.1007/s11064-011-0593-0

80. Sponne I, Fifre A, Koziel V, Kriem B, Oster T, Pillot T. Humanin rescues cortical neurons from prion-peptide-induced apoptosis. Mol Cell Neurosci (2004) 25:95-102. doi:10.1016/j.mcn.2003.09.017

81. Cui AL, Li JZ, Feng ZB, Ma GL, Gong L, Li CL, et al. Humanin rescues cultured rat cortical neurons from NMDA-induced toxicity not by NMDA receptor. ScientificWorldJournal (2014) 2014:341529. doi:10.1155/2014/341529

82. Pagidipati NJ, Gaziano TA. Estimating deaths from cardiovascular disease: a review of global methodologies of mortality measurement. Circulation (2013) 127:749-56. doi:10.1161/CIRCULATIONAHA.112.128413

83. Finegold JA, Asaria P, Francis DP. Mortality from ischaemic heart disease by country, region, and age: statistics from World Health Organisation and United Nations. Int J Cardiol (2013) 168:934-45. doi:10.1016/j.ijcard. 2012.10.046

84. Thom T, Haase N, Rosamond W, Howard VJ, Rumsfeld J, Manolio T, et al. Heart disease and stroke statistics - 2006 update: a report from the American Heart Association Statistics Committee and Stroke Statistics Subcommittee. Circulation (2006) 113:e85-151. doi:10.1161/CIRCULATIONAHA.105. 171600

85. Cowie CC, Rust KF, Ford ES, Eberhardt MS, Byrd-Holt DD, Li C, et al. Full accounting of diabetes and pre-diabetes in the U.S. population in 1988-1994 and 2005-2006. Diabetes Care (2009) 32:287-94. doi:10.2337/dc08-1296

86. Gong Z, Muzumdar RH. Pancreatic function, type 2 diabetes, and metabolism in aging. Int J Endocrinol (2012) 2012:320482. doi:10.1155/2012/320482

87. Cowie CC, Rust KF, Byrd-Holt DD, Eberhardt MS, Flegal KM, Engelgau MM, et al. Prevalence of diabetes and impaired fasting glucose in adults in the U.S. population: National Health And Nutrition Examination Survey 1999-2002. Diabetes Care (2006) 29:1263-8. doi:10.2337/dc06-0062

88. Maedler K, Schumann DM, Schulthess F, Oberholzer J, Bosco D, Berney T, et al. Aging correlates with decreased beta-cell proliferative capacity and enhanced sensitivity to apoptosis: a potential role for Fas and pancreatic duodenal homeobox-1. Diabetes (2006) 55:2455-62. doi:10.2337/db05-1586

89. Kadowaki T. Insights into insulin resistance and type 2 diabetes from knockout mouse models. J Clin Invest (2000) 106:459-65. doi:10.1172/JCI10830

90. Ford ES, Giles WH, Dietz WH. Prevalence of the metabolic syndrome among US adults: findings from the third National Health and Nutrition Examination Survey. JAMA (2002) 287:356-9. doi:10.1001/jama.287.3.356

91. Hojlund K. Metabolism and insulin signaling in common metabolic disorders and inherited insulin resistance. Dan Med J (2014) 61:B4890. 
92. Firneisz G. Non-alcoholic fatty liver disease and type 2 diabetes mellitus: The liver disease of our age? World J Gastroenterol (2014) 20:9072-89. doi:10.3748/wjg.v20.i27.9072

93. Kalaria RN, Maestre GE, Arizaga R, Friedland RP, Galasko D, Hall K, et al. Alzheimer's disease and vascular dementia in developing countries: prevalence, management, and risk factors. Lancet Neurol (2008) 7:812-26. doi:10.1016/ S1474-4422(08)70169-8

94. Driver JA, Djousse L, Logroscino G, Gaziano JM, Kurth T. Incidence of cardiovascular disease and cancer in advanced age: prospective cohort study. BMJ (2008) 337:a2467. doi:10.1136/bmj.a2467

95. Coresh J, Selvin E, Stevens LA, Manzi J, Kusek JW, Eggers P, et al. Prevalence of chronic kidney disease in the United States. JAMA (2007) 298:2038-47. doi:10.1001/jama.298.17.2038

96. Bruunsgaard H, Pedersen BK. Age-related inflammatory cytokines and disease. Immunol Allergy Clin North Am (2003) 23:15-39. doi:10.1016/S0889-8561(02) 00056-5

97. Woods JA, Wilund KR, Martin SA, Kistler BM. Exercise, inflammation and aging. Aging Dis (2012) 3:130-40.

98. de Magalhaes JP. How ageing processes influence cancer. Nat Rev Cancer (2013) 13:357-65. doi:10.1038/nrc3497

99. Maximov V, Martynenko A, Hunsmann G, Tarantul V. Mitochondrial 16S rRNA gene encodes a functional peptide, a potential drug for Alzheimer's disease and target for cancer therapy. Med Hypotheses (2002) 59:670-3. doi:10.1016/S0306-9877(02)00223-2

100. Hartmann TB, Mattern E, Wiedemann N, van Doorn R, Willemze R, Niikura T, et al. Identification of selectively expressed genes and antigens in CTCL. Exp Dermatol (2008) 17:324-34. doi:10.1111/j.1600-0625.2007.00637.x

101. Kokura K, Sun L, Bedford MT, Fang J. Methyl-H3K9-binding protein MPP8 mediates E-cadherin gene silencing and promotes tumour cell motility and invasion. EMBO J (2010) 29:3673-87. doi:10.1038/emboj.2010.239

102. Blaney SM, Bernstein M, Neville K, Ginsberg J, Kitchen B, Horton T, et al. Phase I study of the proteasome inhibitor bortezomib in pediatric patients with refractory solid tumors: a Children's Oncology Group study (ADVL0015). J Clin Oncol (2004) 22:4804-9. doi:10.1200/JCO.2004.12.185

103. Messinger Y, Gaynon P, Raetz E, Hutchinson R, Dubois S, Glade-Bender J, et al. Phase I study of bortezomib combined with chemotherapy in children with relapsed childhood acute lymphoblastic leukemia (ALL): a report from the therapeutic advances in childhood leukemia (TACL) consortium. Pediatr Blood Cancer (2010) 55:254-9. doi:10.1002/pbc.22456
104. Muscal JA, Thompson PA, Horton TM, Ingle AM, Ahern CH, McGovern RM, et al. A phase I trial of vorinostat and bortezomib in children with refractory or recurrent solid tumors: a Children's Oncology Group phase I consortium study (ADVL0916). Pediatr Blood Cancer (2013) 60:390-5. doi:10.1002/pbc.24271

105. Wu S, De Luca F. Inhibition of the proteasomal function in chondrocytes down-regulates growth plate chondrogenesis and longitudinal bone growth. Endocrinology (2006) 147:3761-8. doi:10.1210/en.2005-1672

106. Zaman F, Menendez-Benito V, Eriksson E, Chagin AS, Takigawa M, Fadeel B, et al. Proteasome inhibition up-regulates p53 and apoptosis-inducing factor in chondrocytes causing severe growth retardation in mice. Cancer Res (2007) 67:10078-86. doi:10.1158/0008-5472.CAN-06-3982

107. Zaman F, Fadeel B, Savendahl L. Proteasome inhibition therapies in childhood cancer. Leukemia (2008) 22:883-4. doi:10.1038/sj.leu.2404997

108. Eriksson E, Wickstrom M, Perup LS, Johnsen JI, Eksborg S, Kogner P, et al. Protective role of humanin on bortezomib-induced bone growth impairment in anticancer treatment. J Natl Cancer Inst (2014) 106:djt459. doi:10.1093/jnci/ djt459

Conflict of Interest Statement: This work is supported by National Institute of Health Grant R-01 AG035114 to Radhika Muzumdar. Dr. Radhika Muzumdar is an inventor on patents and patent applications covering the use of humanin and humanin analogs for the treatment of diabesity, myocardial infarction, and insulin secretion. Some of these patents and patent applications have been licensed to a startup company in which she has a financial interest. The other co-authors declare that the research was conducted in the absence of any commercial or financial relationships that could be construed as a potential conflict of interest.

Received: 10 September 2014; accepted: 22 November 2014; published online: 04 December 2014

Citation: Gong Z, Tas E and Muzumdar R (2014) Humanin and age-related diseases: a new link? Front. Endocrinol. 5:210. doi: 10.3389/fendo.2014.00210

This article was submitted to Pediatric Endocrinology, a section of the journal Frontiers in Endocrinology.

Copyright (C) 2014 Gong, Tas and Muzumdar. This is an open-access article distributed under the terms of the Creative Commons Attribution License (CC BY). The use, distribution or reproduction in other forums is permitted, provided the original author(s) or licensor are credited and that the original publication in this journal is cited, in accordance with accepted academic practice. No use, distribution or reproduction is permitted which does not comply with these terms. 